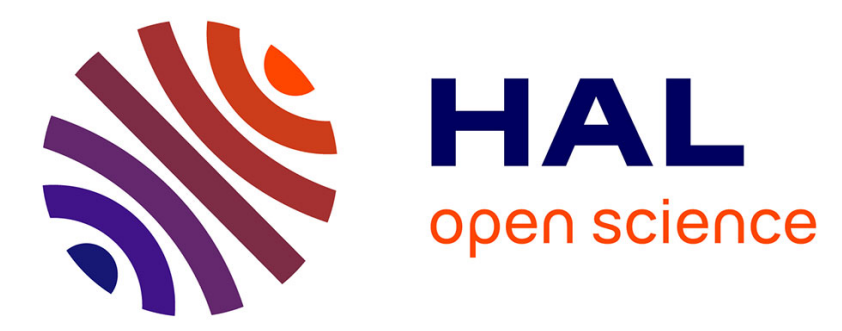

\title{
MICROWAVE ABSORPTION AND STATIC MAGNETIC PROPERTIES OF COPRECIPITATED BARIUM FERRITE
}

\author{
W. Roos, H. Haak, C. Voigt, K. Hempel
}

\section{- To cite this version:}

W. Roos, H. Haak, C. Voigt, K. Hempel. MICROWAVE ABSORPTION AND STATIC MAGNETIC PROPERTIES OF COPRECIPITATED BARIUM FERRITE. Journal de Physique Colloques, 1977, 38 (C1), pp.C1-35-C1-37. 10.1051/jphyscol:1977106 . jpa-00216965

HAL Id: jpa-00216965

https://hal.science/jpa-00216965

Submitted on 1 Jan 1977

HAL is a multi-disciplinary open access archive for the deposit and dissemination of scientific research documents, whether they are published or not. The documents may come from teaching and research institutions in France or abroad, or from public or private research centers.
L'archive ouverte pluridisciplinaire HAL, est destinée au dépôt et à la diffusion de documents scientifiques de niveau recherche, publiés ou non, émanant des établissements d'enseignement et de recherche français ou étrangers, des laboratoires publics ou privés. 


\title{
MICROWAVE ABSORPTION AND STATIC MAGNETIC PROPERTIES OF COPRECIPITATED BARIUM FERRITE
}

\author{
W. ROOS, H. HAAK, C. VOIGT and K. A. HEMPEL \\ Institut für Werkstoffe der Elektrotechnik, RWTH Aachen, West-Germany
}

\begin{abstract}
Résumé. - On a étudié du ferrite de barium préparé par coprécipitation chimique en mesurant l'aimantation à saturation et des propriétés aux hyperfréquences. On a trouvé une absorption par résonance dans un champ négatif, comme le prévoit la théorie du domaine unique. Le champ coercitif ${ }_{J} H_{\mathrm{c}}$ et l'aimantation à saturation $\sigma_{\mathrm{s}}$ peuvent être améliorées par un traitement à l'acide ; on a obtenu des valeurs de $J H_{c}=6400$ Oe et $\sigma_{\mathrm{s}}=70,7 \mathrm{emu} / \mathrm{g}$. Le frittage classique aussi bien que le frittage rapide à chaud conduisent à l'obtention de fortes densités et de bonnes propriétés magnétiques. On a pu atteindre une densité de $5,02 \mathrm{~g} / \mathrm{cm}^{3}$ et un produit $(B H)_{\max }$ de $1,4 \mathrm{MGOe}$ en utilisant le pressage à chaud.
\end{abstract}

\begin{abstract}
Barium ferrite prepared by chemical coprecipitation has been investigated with microwave and static magnetization measurements. The resonance absorption in negative field, predicted by the single domain theory, has been found. The coercive force $J H_{\mathrm{c}}$ and the saturation magnetization $\sigma_{\mathrm{s}}$ can be improved with acid treatment, values of ${ }_{J} H_{\mathrm{e}}=6400 \mathrm{Oe}$ and $\sigma_{\mathrm{s}}=70.7 \mathrm{emu} / \mathrm{g}$ are obtained. Both conventional sintering and rapid hot-pressing lead to a high density and good magnetic properties. A density of $\rho=5.02 \mathrm{~g} / \mathrm{cm}^{3}$ and a maximum energy product of $(B H)_{\max }=1.4 \mathrm{MGOe}$ were achieved by rapid hot-pressing.
\end{abstract}

1. Introduction. - The magnetic properties of barium ferrite prepared by chemical coprecipitation approach very closely the results predicted by the Stoner-Wohlfarth model [1, 2]. This can most directly be recognized from the hysteresis curve for which a coercive field of $6 \mathrm{kOe}$ can easily be achieved. Other magnetic properties should be influenced in a similar way. We have measured the microwave absorption, since it is known that the absorption depends strongly on the magnetization structure present in the particles of a polycrystalline material. It is found that the microwave properties of coprecipitated barium ferrite differ significantly from those of conventionally prepared barium ferrite. Furthermore, we have investigated the influence of acid treatment and sintering on high coercive powder.

2. Microwave experiments. - In a sample of noninteracting single-domain crystallites with positive uniaxial anisotropy constant $K_{1}$ the usual ferromagnetic resonance occurs at $H \approx H_{\mathrm{A}}\left(H_{\mathrm{A}}=2 K_{1} / M_{\mathrm{s}}\right)$, if the microwave frequency is sufficiently below the natural resonance frequency and if the sample has previously been saturated. When the field is reversed a pronounced additional absorption peak has been predicted to occur at $H \approx-H_{\mathrm{A}} / 2$ [3]. This absorption occurs because the equilibrium position of the magne- tization becomes less stable in negative fields, which leads to a lowering of the resonance frequency. The values of $H$ for which the resonance frequency is zero are those at which the discontinuous jumps of the magnetization take place.

In conventionally prepared barium ferrite the absorption peak in negative field has not been found. Coprecipitated barium ferrite, however, does display resonance absorption at $H \approx-H_{\mathrm{A}} / 2$, figure 1 [4]. One can conclude that the magnetization of a large number of particles is reversed by coherent rotation.

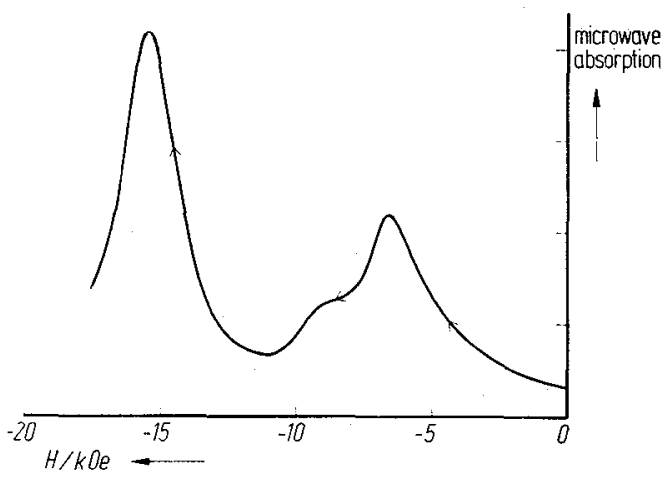

Frg. 1. - Microwave absorption of polycrystalline chemically coprecipitated $\mathrm{BaFe}_{12} \mathrm{O}_{19} .15 \mathrm{~min}$. treatment in $\mathrm{HCl}$ $f=11.9 \mathrm{GHz}$. Field decreasing from 0 to $-18 \mathrm{kOe}$. 
The maximum of the absorption is lower than predicted by the theory. This is remarkable since the measured hysteresis of the magnetization can be approximated by the single domain theory much better [1, 2]. Apparently the microwave absorption is more sensitive to deviations from the ideal behaviour. This is supported by the observation that the resonance in negative field decreases if the powder is slightly ground by hand in a mortar. It is likely that this treatment induces defects in the crystallites which leads to a non coherent reversal process.

3. Treatment with acid ( $\mathbf{H C l})$. - The coercive force of coprecipitated barium ferrite is very high compared to that of conventionally ball-milled barium ferrite. Nevertheless there is still a slight difference to the ideal single domain behaviour. To improve the magnetic properties the coprecipitated powder was treated for various times in an aqueous solution of $\mathrm{HCl}$. After a treatment of $15 \mathrm{~min}$. in a $50 \%$ aqueous solution we estimate the proportion of dissolved material to be $\approx 70 \%$ A saturation magnetization of $\sigma_{\mathrm{s}}=70.7 \mathrm{emu} / \mathrm{g}$ and a coercive force of $6.4 \mathrm{kOe}$ were obtained, figure 2 . The coercive force is one of the

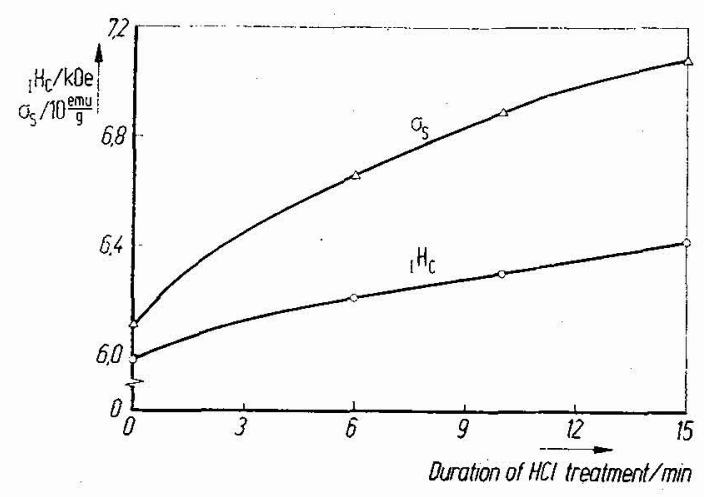

FIG. 2. - Influence of treatment in a $50 \% \mathrm{HCl}$ solution on magnetic properties of coprecipitated $\mathrm{BaFe}_{12} \mathrm{O}_{19}$.

highest reported for unoriented barium ferrite. Acid treatment might lead to a reduction of surface defects and sharp edges of the grains which usually favour the formation of reversed domains. In addition, the improvement may be connected with the disappearence of other phases which dissolve in $\mathrm{HCl}$ much more easily than barium ferrite.

To get more information about this high coercive powder we studied the shape and size of the crystallites by transmission electron microscopy. Figure 3 shows some micrographs. The particles have an average dimension of $0.1 \mu \mathrm{m}$ and a narrow size distribution $(0.02-0.15 \mu \mathrm{m})$. The hexagonal shape of the crystallites can be recognized from a few particles having their $c$-axis apparently parallel to the incident electron beam.

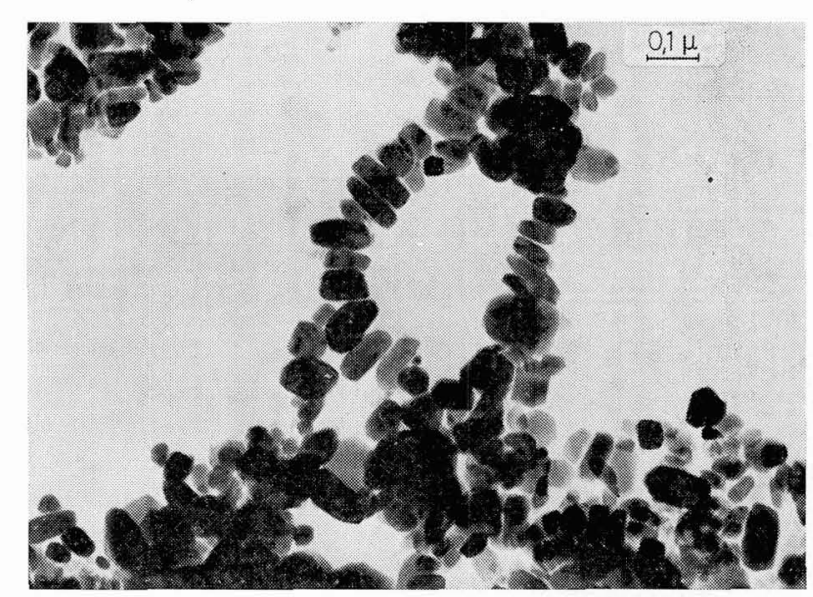

(a)

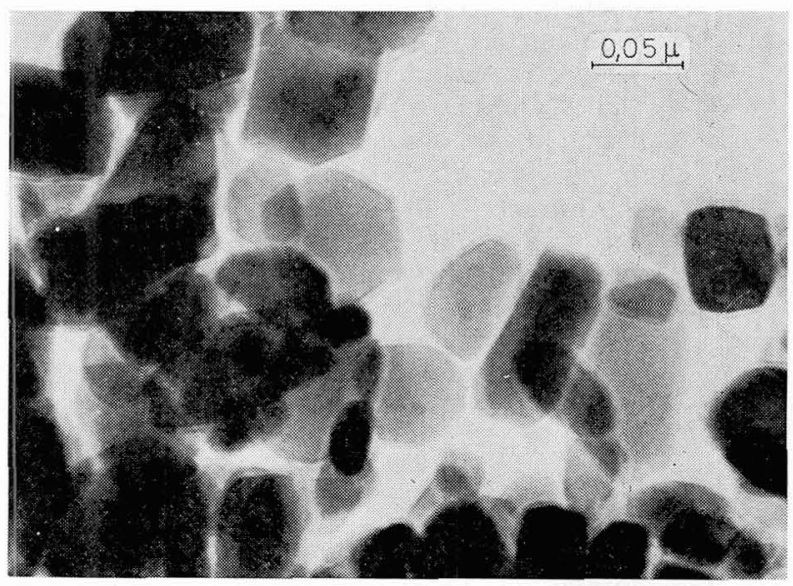

(b)

Fig. 3. - Transmission electron micrographs of coprecipitated $\mathrm{BaFe}_{12} \mathrm{O}_{19}$ after a 10 min. treatment with a $50 \% \mathrm{HCl}$ solution.

Furthermore, an interesting aspect is the agglomeration of particles under their mutual interactions. These interactions seem to cause a more or less complete magnetic flux closure.

4. Densification characteristics. - Because of its small grain size coprecipitated barium ferrite powder can be well used as starting material to obtain sintered magnets. We have investigated the densification properties of coprecipitated powder by rapid hotpressing and the conventional sintering process. In the latter case isotropic samples were prepared from prepressed powder $\left(2.5 \mathrm{t} / \mathrm{cm}^{2}\right)$ by sintering for $2 \mathrm{~h}$ at various temperatures. A pressure induced anisotropy which has been reported in [2] could not be detected. The best magnetic properties were obtained for samples sintered at $1100^{\circ} \mathrm{C}$ for $2 \mathrm{~h}: \rho=4.60 \mathrm{~g} / \mathrm{cm}^{3}$, ${ }_{J} H_{\mathrm{c}}=5.45 \mathrm{kOe},{ }_{B} H_{\mathrm{c}}=1.8 \mathrm{kOe}, B_{\mathrm{r}}=2.06 \mathrm{kG}$, $(B H)_{\max }=0.93$ MOe. From figure 4 which show the density and the magnetic properties versus sintering 


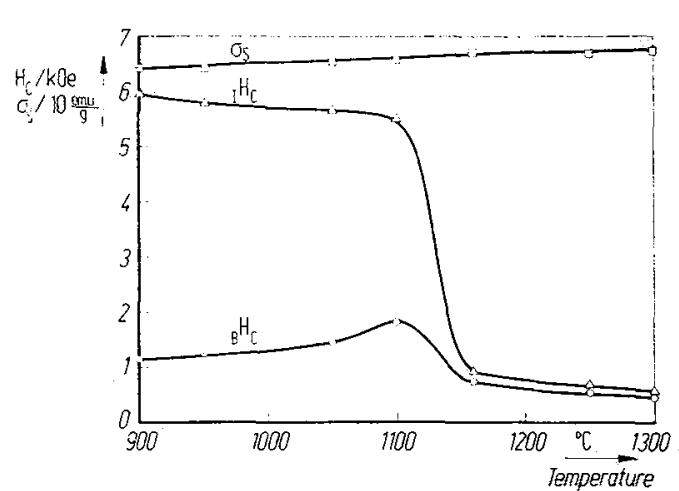

(a)

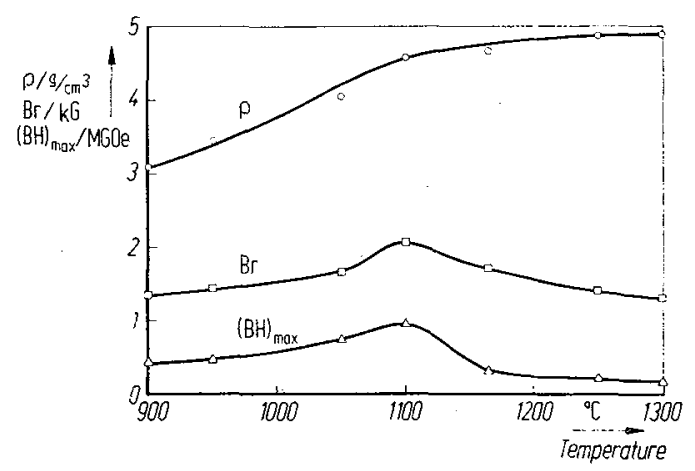

(b)

FIG. 4. - Density and magnetic properties of prepressed coprecipitated $\mathrm{BaFe}_{12} \mathrm{O}_{19}$ after a $2 \mathrm{~h}$ sintering. temperature, it can be seen that unoriented bulk samples prepared from coprecipitated barium ferrite exhibit magnetic properties not far from those prepared by the ordinary powder process which however usually involves a higher sintering temperature. Sintering at about $1150^{\circ} \mathrm{C}$ considerably deteriorates the magnetic properties, especially the intrinsic coercivity which decreases from ${ }_{J} H_{\mathrm{c}}>5.5 \mathrm{kOe}$ to ${ }_{J} H_{\mathrm{c}}<1 \mathrm{kOe}$.

In order to study the densification process of coprecipitated barium ferrite during rapid hot-pressing we used an apparatus similar to the one described in [5]. Unoriented samples with a starting density of $\rho=4.0 \mathrm{~g} / \mathrm{cm}^{3}$ and a coercivity of ${ }_{J} H_{\mathrm{c}}=5.45 \mathrm{kOe}$ were kept at constant pressure $\left(400 \mathrm{kp} / \mathrm{cm}^{2}\right)$ and constant temperature $\left(1050^{\circ} \mathrm{C}\right)$ for various pressing times $(0-90 \mathrm{~s})$. Our measurements show that the densification process is mainly accomplished in the first minute. The intrinsic magnetic properties ${ }_{5} H_{\mathrm{c}}$ and $\sigma_{\mathrm{s}}$ of the hot-pressed samples are nearly the same as those of the starting material. A typical sample, hot-pressed for $90 \mathrm{~s}$, exhibits the following properties : $\rho=5.02 \mathrm{~g} / \mathrm{cm}^{3},{ }_{J} H_{\mathrm{c}}=4.8 \mathrm{kOe},{ }_{B} H_{\mathrm{c}}=2.14 \mathrm{kOe}$, $B_{\mathrm{r}}=2.65 \mathrm{kG},(B H)_{\max }=1.4 \mathrm{MGOe}$. The relatively high values of $B_{\mathrm{r}}$ and $(B H)_{\max }$ compared with values of isotropic sintered $\mathrm{BaFe}_{12} \mathrm{O}_{1}$, presumably result from oriented grain growth induced by hot-pressing.

Acknowledgments. - The authors would like to thank Dr. H. Stäblein for pressing some of the samples and Dr. W.-G. Burchard for the electron micrographs.

\section{References}

[1] MeE, C. and Jeschke, J. C., J. Appl. Phys. 34 (1963) 1271.

[2] Haneda, K., Miyakawa, C. and Komma, H., J. Am. Cer. Soc. 57 (1974) 354.

[3] Hempel, K. A., Z. Angew. Phys. 28 (1970) 280.

[4] HAAK, H., Thesis RWTH, Aachen (1975). The additional resonance absorption in negative field is also found in powder not treated with $\mathrm{HCl}$; the effect, however, is much smaller than the effect in figure 1 and is therefore not shown here.

[5] Oron, M. and RAMON, P., IEEE Trans. Mag. MAG-11 (1975) 1452. 